\title{
Remoção cirúrgica de sialolito no ducto da glândula submandibular: relato de caso
}

\author{
Surgical procedure to remove a sialolith \\ in the submandibular gland duct: case report \\ La extirpación quirúrgica de sialolito del conducto \\ de la glándula submandibular: reporte de un caso \\ Rodrigo dos Santos PEREIRA ${ }^{1}$ \\ João Paulo BONARDI ${ }^{2}$ \\ Jonathan Ribeiro DA SILVA ${ }^{3}$ \\ Carlos Fernando de Almeida Barros MOURÃO \\ Fernando Isquierdo DE SOUZA ${ }^{5}$ \\ Rafael Meira PIMENTEL ${ }^{6}$ \\ ${ }^{1} D D S, M S c$, PhD Staff do Serviço de Cirurgia e Traumatologia do Hospital Geral de Nova Iguaçu - RJ \\ Especialista em Cirurgia e Traumatologia Bucomaxilofacial \\ Mestre e Doutor em Odontologia pela Faculdade de Odontologia de Araçatuba, Universidade Estadual Paulista, UNESP \\ Fellow AO pela Universitätsklinikum Eppendorf. Hamburgo, Alemanha. \\ ${ }^{2} D D S, M S c$ Especialista em Cirurgia e Traumatologia Bucomaxilofacial \\ Mestre em Odontologia pela Faculdade de Odontologia de Araçatuba, Universidade Estadual Paulista, UNESP \\ ${ }^{3} \mathrm{DDS}, \mathrm{MSc}$ Mestre em Odontologia pela UNIGRANRIO \\ Doutorando em Odontologia pela Faculdade de Odontologia de Araçatuba, Universidade Estadual Paulista, UNESP \\ ${ }^{4}$ DDS, MSc Especialista em Estomatologia e Implantodontia \\ Mestre em Ciências Cirúrgicas pela UFRJ \\ Doutorando em Odontologia pela UFF \\ ${ }^{5}$ DDS, MSc Mestre em Odontologia pela Faculdade de Odontologia de Araçatuba Universidade Estadual Paulista, UNESP \\ ${ }^{6} D D S$, MSc Especialista em Cirurgia e Traumatologia Bucomaxilofacial \\ Mestre em Odontologia pela São Leopoldo Mandic
}

\begin{abstract}
Resumo
A sialolitíase é uma doença que ocorre nas glândulas salivares através da formação de cálculos que impedem o fluxo e ocasionam infecções recorrentes. O tratamento dessas lesões pode ser realizado pela abertura cirúrgica do ducto, litotripsia, laser de Dióxido de Carbono e a sialodectomia. O objetivo deste artigo é demonstrar um caso clínico de remoção de 2 cálculos salivares no ducto de Wharton da glândula submandibular direita através da sua abertura e a transposição do óstio. Assim, após 1 ano, a técnica mostrou-se promissora pois não houve recorrências e o fluxo salivar manteve-se permeável no novo óstio.

Descritores: Cálculos das Glândulas Salivares; Terapêutica; Cirurgia Bucal.
\end{abstract}

\begin{abstract}
Sialolithiasis is a disease that occurs in salivary glands with the formation of stones interrupting the salivary flow and causing recurrent infections. Its treatment can be performed by surgical procedures through duct opening, liptotripsy, carbon dioxide laser and sialodenectomy. The aim of this article is to demonstrate a clinical case of 2 salivary calculi remove in the right submandibular gland by the surgical opening and transposition of the ostium. Thus, after 1 year, the technique was promising because there were no recurrences and the salivary flow remained permeable in the ostium.

Descriptors: Salivary Gland Calculi; Therapeutics; Surgery, Oral.
\end{abstract}

\section{Resumen}

El sialolitiasis es una enfermedad que se produce en las glándulas salivales mediante la formación de cálculos que impiden el flujo y causan infecciones recurrentes. El tratamiento de estas lesiones puede ser realizada por la abertura quirúrgica del conducto, la litotricia, láser de dióxido de carbono y sialodectomia. El propósito de este artículo es mostrar un caso de eliminación de cálculos 2 salival en la glándula submandibular derecha del conducto de Wharton, a través de su apertura y la transposición del ostium. Así que después de un año, la técnica mostró promesa como no hubo recurrencias y el flujo salival se mantuvo permeable en el nuevo orificio.

Descriptores: Cálculos de las Glándulas Salivales; Terapéutica; Cirugía Bucal.

\section{INTRODUÇ̃̃O}

A sialolitíase é uma doença das glândulas salivares onde ocorrem a formação de cálculos ou sialolitos ${ }^{1}$. Afeta adultos entre a quarta e sexta década de vida com frequência de 12:1000 e com maior prevalência ao sexo masculino $(2: 1)^{2}$. Na grande maioria dos casos, de 70 a $80 \%$, apenas um sialolitos é encontrado. Mais de dois cálculos ocorrem em até $20 \%$ dos casos e acima de 3 em até $5 \%{ }^{1}$. Porém, múltiplos sialolitos já foram reportados na literatura com até 268 pedras encontradas na glândula sublingual ${ }^{1,3}$.

A formação dos sialolitos pode ocorrer no ducto ou no interior da glândula ${ }^{4}$. A glândula submandibular é a mais acometida, com até $90 \%$ de incidência, seguido da glândula parótida com até $20 \%$ e da sublingual com apenas $1 \% 5$. Esta alta taxa referente à glândula submandibular deve-se à anatomia tortuosa e longa do ducto Wharton que possui uma direção anterior e superior para o soalho bucal além de, ter o calibre menor próximo a carúncula ${ }^{4}$. Diferentemente, o ducto de Stensen possui um trajeto retilíneo, uniforme e a ajuda dos músculos da mastigação, que o sobrepõe, no fluxo salivar ${ }^{4}$.

O cálculo formado pode levar o paciente a referir dores recorrentes e infecção no soalho bucal ${ }^{6}$. As queixas álgicas ocorrem principalmente durante as refeições pois, há um aumento da pressão intraglandular resultando em aumento da secreção salivar da glândula obstruída ${ }^{5}$. Além disso, pode haver a diminuição do fluxo salivar, aumento de volume local e, nos casos mais graves, disfagia ${ }^{3,7}$.

Segundo Jardim et al. ${ }^{8}$ os exames de imagem que podem ser utilizados para verificar os cálculos salivares são as radiografias convencionais. As radiografias panorâmicas e 
oclusais apresentam precisão e acurácia satisfatória na detecção dos sialolitos ${ }^{9}$. Contudo, lesões pouco calcificadas somente serão observadas mais precisamente utilizando outros meios como ultrassom, tomografia computadorizada e ressonância nuclear magnética ${ }^{10}$.

O tratamento da sialolitíase na glândula submandibular poderá ser por meio da remoção cirúrgica do sialolito através da abertura cirúrgica do ducto; a litotripsia, que fragmenta o cálculo por meio de ondas de choque; o uso de laser de dióxido de carbono $\left(\mathrm{CO}_{2}\right)$; e por ultimo, a sialodenectomia. Esta consiste na remoção completa da glândula submandibular nos casos onde o cálculo estiver no interior da mesma ou porção proximal do ducto ${ }^{4}$.

O objetivo deste artigo é demonstrar a remoção cirúrgica de um sialolito no interior do ducto de Wharton, a transposição do óstio e o acompanhamento de 1 ano de pósoperatório.

\section{CASO CLÍNICO}

Paciente gênero feminino, leucoderma, 44 anos compareceu ao ambulatório de Cirurgia e Traumatologia Bucomaxilofacial do Hospital Geral de Nova Iguaçu referindo dores em soalho bucal. Durante o exame clínico, foi observado um aumento de volume sublingual no lado direito com queixas álgicas durante palpação (Figura 1). Durante a coleta da história clínica, a paciente informou que houve episódios de aumento de volume submandibular direito quando se alimentava. $\mathrm{Na}$ avaliação da radiografia panorâmica (Figura 2) observou-se a presença de 2 imagens radiopacas sobrepostas pela mandíbula nas regiões entre os elementos dentários 43 e 45 assim como, a radiografia oclusal inferior que também demostrou as mesmas 2 imagens paralelas ao corpo da mandibula (Figura 3).

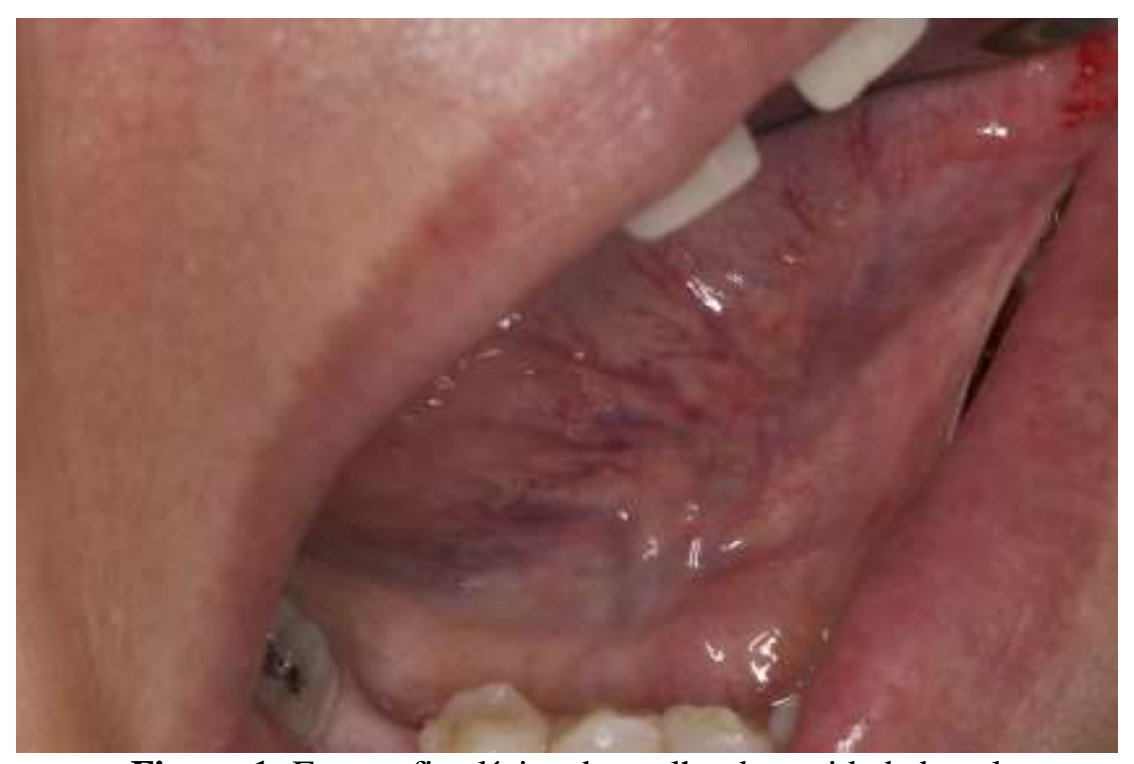

Figura 1: Fotografia clínica do soalho da cavidade bucal demonstrando aumento de volume na região.

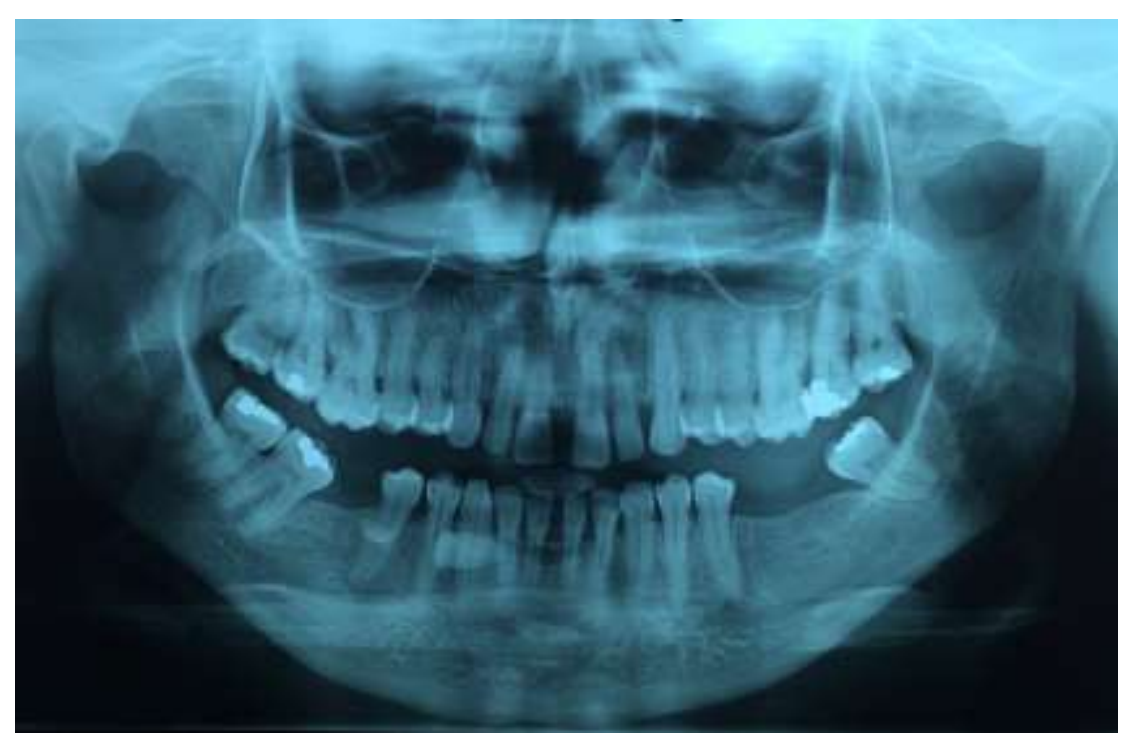

Figura 2: Radiografia panorâmica evidenciando o cálculo salivar na região de elementos 43 a 45 .

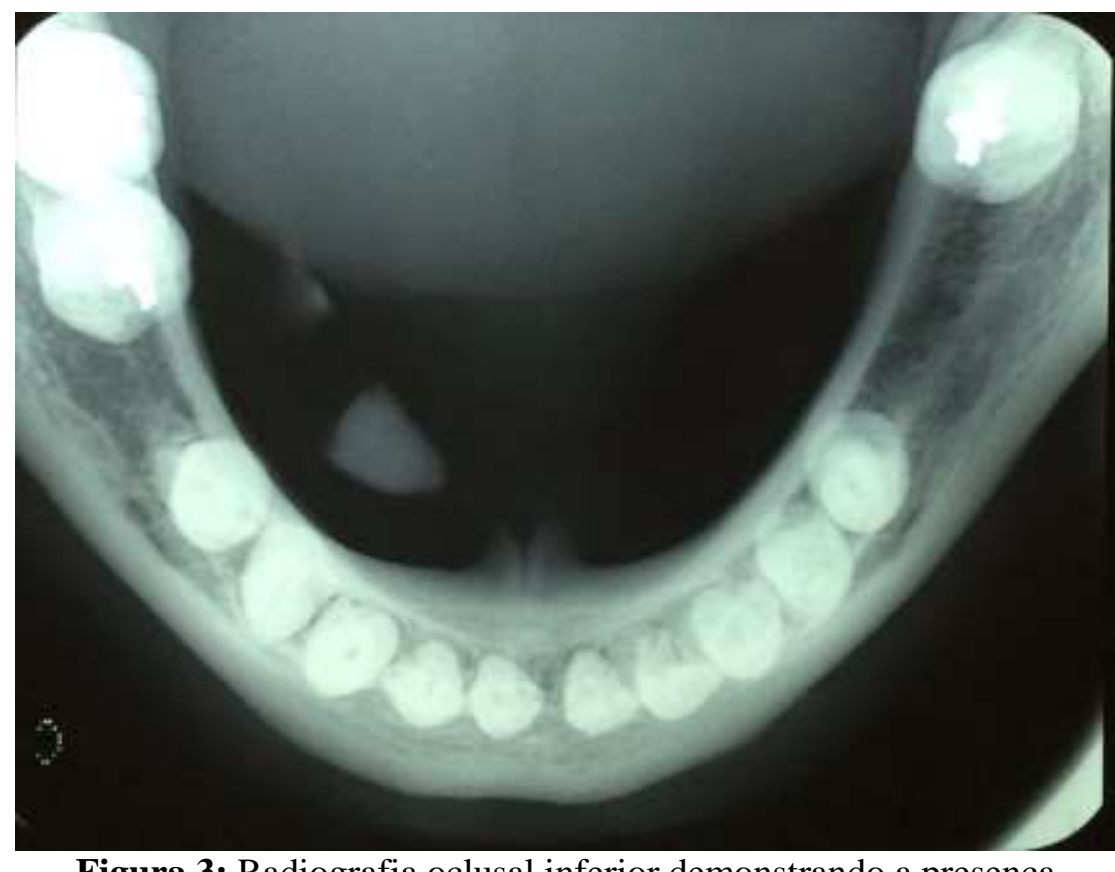

Figura 3: Radiografia oclusal inferior demonstrando a presença de duas imagens radiopacas no soalho bucal.

As informações adquiridas durante a avaliação clínica permitiram concluir o diagnóstico de sialolitíase na parte distal do ducto de Wharton da glândula submandibular direita. O tratamento proposto foi realizar o acesso cirúrgico ao ducto, sob anestesia local, através do bloqueio do nervo lingual direito com lidocaína 2\% com adrenalina 1:100.000 (DFL; Taquara - Rio de Janeiro, Brasil). O acesso foi realizado com uma lâmina de bisturi $\mathrm{n}^{\circ} 15$ (Lamedid; Barueri - São Paulo, Brasil) acoplado a um cabo $n^{\circ} 3$ na mucosa sublingual. Após, os tecidos foram divulsionados com uma tesoura Metzenbaum para identificar o ducto de Wharton com os sialolitos em seu interior. Outra incisão foi feita no ducto para expor os cálculos salivares que foram removidos com uma pinça (Figura 4).

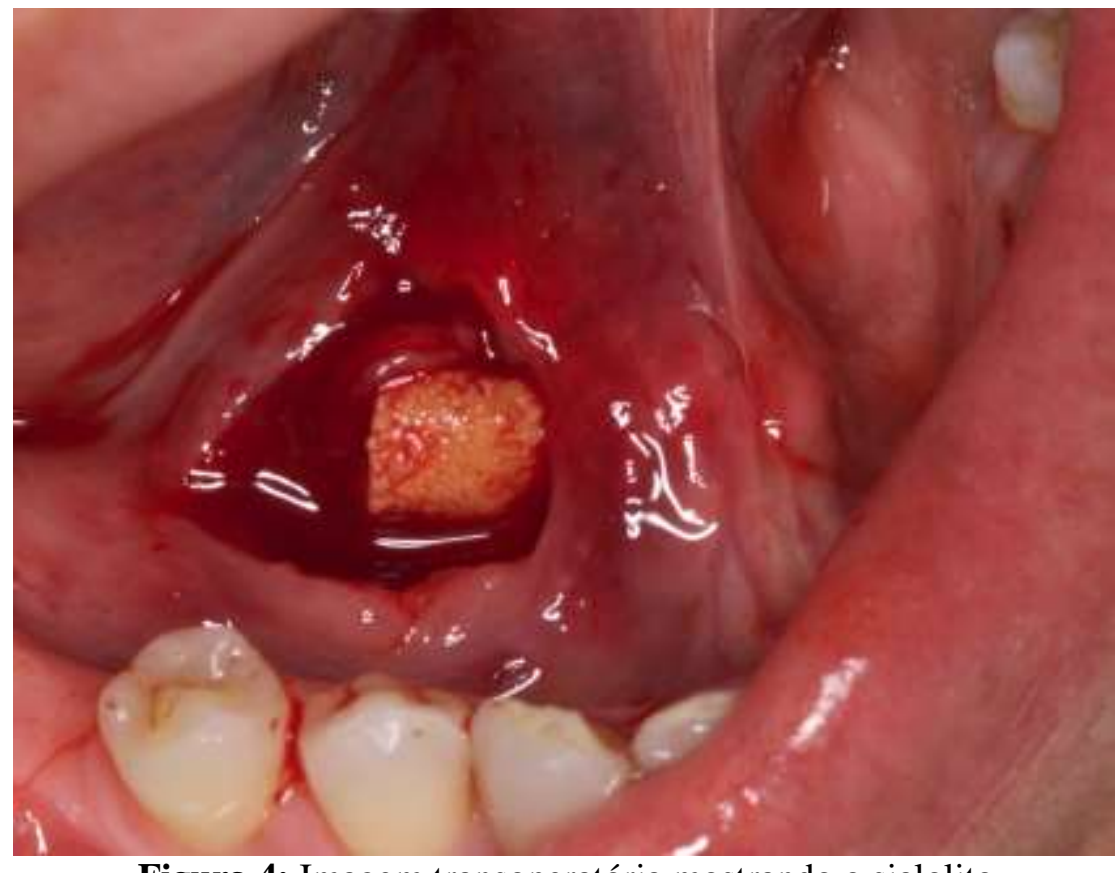

Figura 4: Imagem transoperatória mostrando o sialolito no interior do ducto de Wharton.

Os espécimes apresentavam medidas de 6 x $5 \mathrm{~mm}$ e 3 x $2 \mathrm{~mm}$ (Figura 5). As paredes do ducto foram suturadas com fio de seda 4.0 (Johnson \& Johnson; São Paulo - SP, Brasil) na mucosa adjacente para transposição do óstio do ducto (Figura 6). Durante 3 dias, foram administrados 20 mg de Tilatil ${ }^{\circledR}$ (Roche; Rio de Janeiro - RJ, Brasil) 2 vezes ao dia e Paracetamol 500 mg (EMS; São Paulo - RJ, Brasil) 3 vezes ao dia para redução da dor. A paciente retornou 10 dias depois, na primeira avaliação pós-operatória, para a remoção da sutura apresentando boa higienização e cicatrização da ferida. Após 1 ano de pós-operatório, a paciente não apresentou novos episódios de dores ou aumento de volume e, na avaliação clínica, observou-se 
patência do ducto de Wharton através do fluxo salivar no novo óstio (Figura 7).

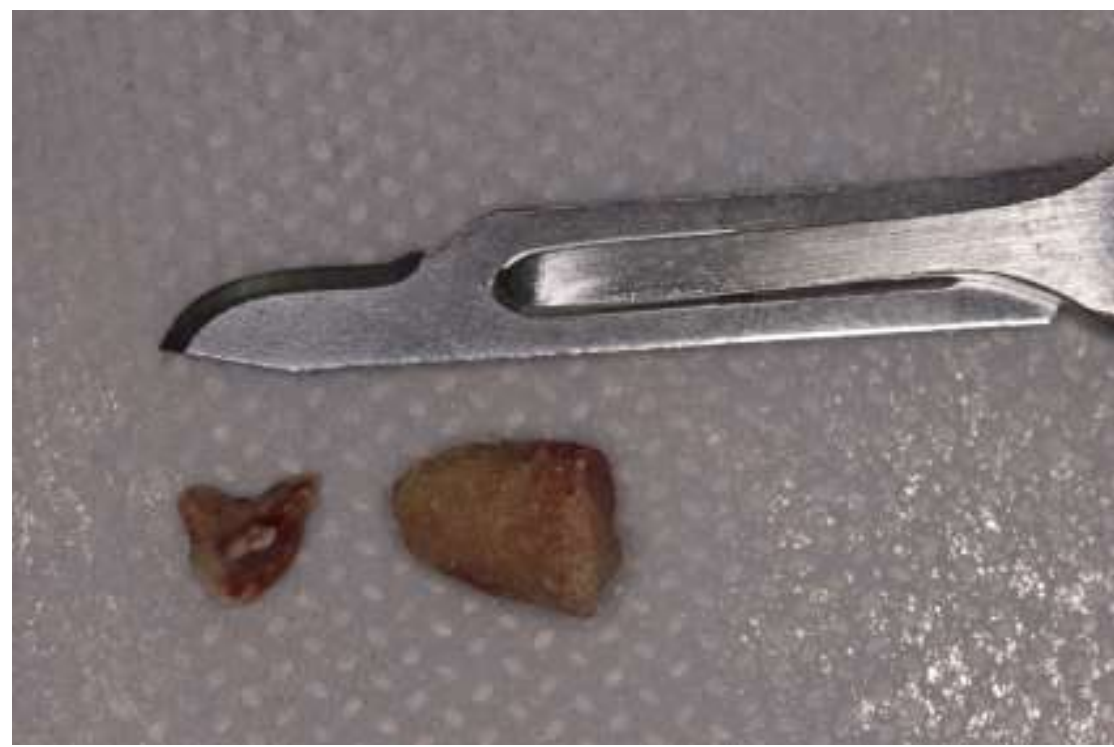

Figura 5: Imagem dos sialolitos após a remoção cirúrgica.

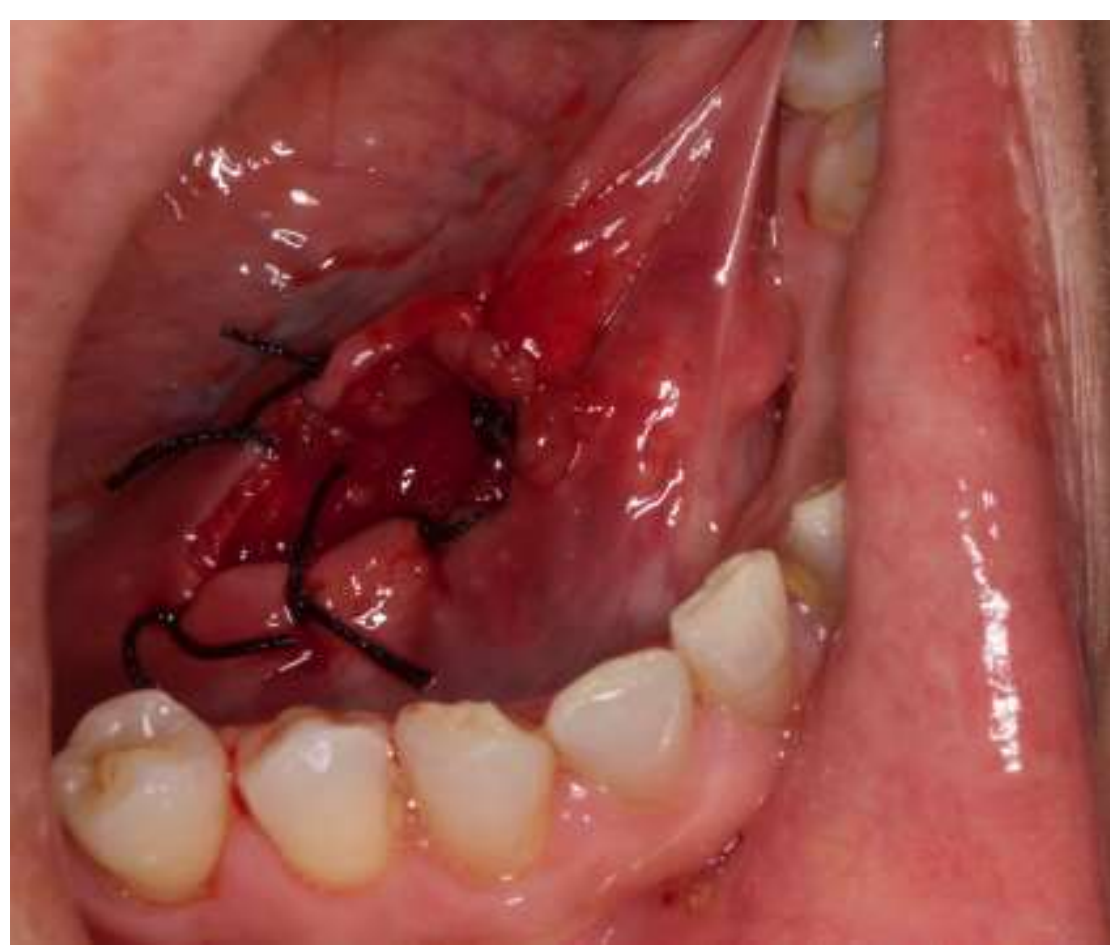

Figura 6: Imagem transoperatória das suturas das paredes do ducto à mucosa do soalho bucal (Transposição do Ostio).

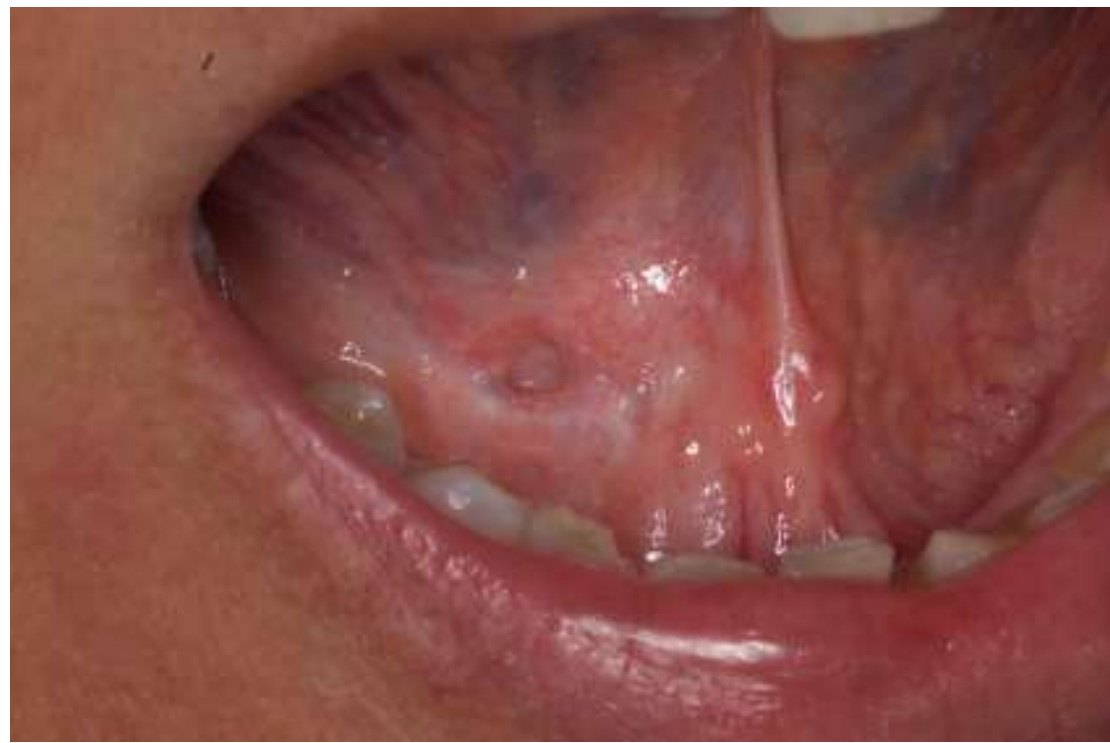

Figura 7: Fotografia clínica de 1 ano de pós-operatório mostrando o novo óstio no soalho bucal.

\section{DISCUSSÃO}

Sialolitos são estruturas calcificadas encontradas nos ductos ou interior das glândulas salivares impedindo o fluxo salivar $^{7}$. São compostos de material inorgânico como a hidroxiapatita e também de material orgânico como glicoproteínas, lipídios e carboidratos ${ }^{11}$. Kraaij et al. ${ }^{11}$ concluíram que doenças sistêmicas e o uso de medicações não são fatores causadores da sialolitíase ${ }^{12}$. A formação do sialolito ocorre com a retenção salivar pela anatomia presente no ducto seguido da supersaturação da saliva, déficit dos inibidores de cristalização e o aumento do $\mathrm{pH}$ decorrente da infecção bacteriana ${ }^{13}$.

O tratamento deverá ser o de menor trauma e o menos invasivo ${ }^{2}$. Os cálculos menores podem ser tratados com sialogogos ou massagem da glândula submandibular, porém, a anatomia do ducto de Wharton assim como seu pequeno óstio, não permitem a sua expulsão. Devido ao tamanho dos cálculos encontrados no presente caso, a melhor opção foi a remoção cirúrgica por meio do acesso direto ao ducto da glândula. A vantagem deste tratamento é a possibilidade de transposição do óstio por meio das suturas do ducto na mucosa adjacente evitando a estenose e manter o fluxo salivar.

As possíveis complicações pós-operatórias são a lesão do nervo lingual e a estenose do ducto ${ }^{14}$ que são evitadas tendo os cuidados com a técnica operatória adequada no transoperatório. A divulsão dos tecidos sublinguais após a incisão da mucosa com a correta identificação do ducto evita a lesão ao nervo lingual. O ducto de Wharton possui direção anterior no soalho bucal enquanto o nervo lingual segue o trajeto em direção à base da língua ${ }^{4}$. A estenose do ducto pode ser evitada de duas formas: a primeira é suturar uma sonda na luz do ducto para que ocorra a epitelização do coto distal formando um novo óstio; a segunda opção é a que utilizamos no presente caso, por meio de suturas do ducto à mucosa adjacente ${ }^{2}$.

\section{CONCLUSÃO}

O caso clínico apresentado teve como objetivo demonstrar a identificação e a técnica cirúrgica para a remoção de sialolitos no ducto da glândula submandibular assim como a forma de manter a patência do ducto para permitir a manutenção do fluxo salivar.

\section{REFERÊNCIAS}

1. Choi J, Kim IK, Oh NS. Multiple sialoliths in sublingual gland: report of a case. Int J Oral Maxillofac Surg. 2002;31(5):562-3.

2. Oliveira T de P, Oliveira IN, Pinheiro EC, Gomes RC, Mainenti P. Giant sialolith of submandibular gland duct treated by excision and ductal repair: a case report. Braz J Otorhinolaryngol. 2016;82(1):112-5.

3. Eyigor H, Osma U, Yilmaz MD, Selcuk OT. Multiple sialolithiasis in sublingual gland causing dysphagia. Am J Case Rep. 2012;13:44-6.

4. Baurmash HD. Submandibular salivary stones: current management modalities. J Oral Maxillofac Surg. 2004 62(3):369-78

5. Lustmann J, Regev E, Melamed Y. Sialolithiasis. A survey on 245 patients and a review of the literature. Int J Oral Maxillofac Surg. 1990;19(3):135-8.

6. Yiu AJ, Kalejaiye A, Amdur RL, Todd Hesham HN, Bandyopadhyay BC. Association of serum electrolytes and smoking with salivary gland stone formation. Int $\mathrm{J}$ Oral Maxillofac Surg. 2016;45(6):764-8.

7. Bernardes Filho F, Martins G, Alves AO, Costa JR, Azulay DR, Azulay-Abulafia L. Rigid swelling of sublingual caruncle area due to the salivary gland duct obstruction by a sialolith. An Bras Dermatol. 2014; 89(6):977-9.

8. Jardim EC, Ponzoni D, de Carvalho PS, Demetrio MR, Aranega AM. Sialolithiasis of the submandibular gland. J Craniofac Surg. 2011; 22(3):1128-31.

9. Kim JH, Aoki EM, Cortes AR, Abdala-Junior R, Asaumi J, Arita ES. Comparison of the diagnostic 
performance of panoramic and occlusal radiographs in detecting submandibular sialoliths. Imaging Sci Dent 2016; 46(2):87-92.

10. Park JS, Sohn JH, Kim JK. Factors influencing intraoral removal of submandibular calculi. Otolaryngol Head Neck Surg. 2006; 135(5):704-9.

11. Kraaij S, Karagozoglu KH, Forouzanfar T, Veerman EC, Brand HS. Salivary stones: symptoms, aetiology, biochemical composition and treatment. $\mathrm{Br}$ Dent $\mathrm{J}$. 2014; 217(11):E23.

12. Kraaij S, Karagozoglu KH, Kenter YA, Pijpe J, Gilijamse M, Brand HS. Systemic diseases and the risk of developing salivary stones: a case control study. Oral Surg Oral Med Oral Pathol Oral Radiol. 2015; 119(5):539-43.

13. Grases F, Santiago C, Simonet BM, Costa-Bauzá A. Sialolithiasis: mechanism of calculi formation and etiologic factors. Clin Chim Acta. 2003; 334(1-2):13136.

14. Fowell C, MacBean A. Giant salivary calculi of the submandibular gland. J Surg Case Rep. 2012; 2012(9):6.

\section{CONFLITO DE INTERESSES}

Os autores declaram não haver conflitos de interesse.

\section{AUTOR PARA CORRESPONDÊNCIA}

Rodrigo dos Santos Pereira

dr.pereira@live.com

Submetido em 16/12/2016 Aceito em 01/01/2017 